\title{
Effect of sodium salts on diffusion of poly(vinyl alcohol) in aqueous solutions
}

\author{
Barbora Filova a,b, Lenka Musilova ${ }^{\text {b,c }}$, Aleš Mracek ${ }^{\mathrm{b}, \mathrm{c}, *}$, M. Luísa Ramos $^{\mathrm{a}}$, Luis M.P. Veríssimo a, \\ Artur J.M. Valente ${ }^{\text {a }}$, Ana C.F. Ribeiro ${ }^{\text {a,*** }}$ \\ a Centro de Química de Coimbra, Department of Chemistry, University of Coimbra, 3004-535 Coimbra, Portugal \\ b Department of Physics and Materials Engineering, Faculty of Technology, Thomas Bata University in Zlín, Vavrečkova 275, 760 01 Zlín, Czech Republic \\ c Centre of Polymer Systems, Thomas Bata University in Zlín, tř. Tomáše Bati 5678, 76001 Zlín, Czech Republic
}

\section{A R T I C L E I N F O}

\section{Article history:}

Received 16 November 2019

Received in revised form 6 January 2020

Accepted 16 February 2020

Available online 19 February 2020

\section{Keywords:}

Diffusion coefficient

Poly (vinyl alcohol)

Sodium chloride

Sodium sulfate

Solutions

Transport properties

\begin{abstract}
A B S T R A C T
The Taylor dispersion technique has been used for measuring the tracer diffusion coefficients, $D_{\text {Tracer, }}^{0}$ for poly (vinyl alcohol) (PVA) in aqueous systems containing two specific electrolytes (i.e., $\mathrm{NaCl}$ and $\mathrm{Na}_{2} \mathrm{SO}_{4}$ ) at three different concentrations $\left(0.020,0.050\right.$ and $\left.0.10 \mathrm{~mol} \mathrm{dm}^{-3}\right)$, and at $25^{\circ} \mathrm{C}$. The selection of these salts has been based on the Hofmeister series of cations and anions, which order the ions with respect to the behavior of some macroscopic properties (such as, surface tension) and that can be interpreted as an effect salting-out or salting-in, depending if the target ions are strongly (kosmotropic) or a weakly hydrated (chaotropic). In this work, we have been used the combination of two kosmotropic ions $\left(\mathrm{Na}_{2} \mathrm{SO}_{4}\right)$ and another one with a kosmotropic cation and a chaotropic anion $(\mathrm{NaCl})$.

These data, complemented by NMR measurements, permit us to have a better understanding about the effect of these sodium salts on transport and thermodynamic behaviour of PVA.
\end{abstract}

(c) 2020 Elsevier B.V. All rights reserved.

\section{Introduction}

Poly(vinyl alcohol) (PVA) is a polymer of great interest because of its many desirable characteristics specifically for a wide range of applications, including pharmaceutical, biomedical, electrochemistry (for example, super-capacitors) [1], and sensors [2,3]. PVA has a relatively simple chemical structure with a pendant hydroxyl group (Fig. 1a). The monomer, vinyl alcohol, does not exist in a stable form, rearranging to its tautomer, acetaldehyde. Therefore, PVA is produced by the polymerization of vinyl acetate to poly(vinyl acetate) (PVAc) followed by the hydrolysis to PVA (Fig. 1b). Once the hydrolysis reaction is not complete, there are PVA with different degrees of hydrolysis (Fig. 1b). For practical purposes, PVA is always a co-polymer of vinyl alcohol and vinyl acetate [4].

PVA is able to form hydrogels, being of particular interest for pharmaceutical and biomedical application. This comes out as a consequence of its non-toxic, non-carcinogenic and bio adhesive characteristics but also because their hydrogels show a high swelling degree and a rubbery and elastic nature [5]. These characteristics

\footnotetext{
* Correspondence to: A. Mracek, Department of Physics and Materials Engineering, Faculty of Technology, Thomas Bata University in Zlín, Vavrečkova 275, 76001 Zlín, Czech Republic.

** Corresponding author.

E-mail addresses: mracek@utb.cz (A. Mracek), anacfrib@ci.uc.pt (A.C.F. Ribeiro).
}

make this polymer appropriate for application such as drug delivery $[6,7]$ and wound dressing [8].

Despite the hydrophilicity of PVA, it has been recently found that PVA either in gel or in aqueous solution act as an amphiphilic polymer. In fact, it has been observed that the solubility of a hydrophobic drug, simvastatin, is enhanced inside PVA gel matrix [9]. This occurs once the PVA adopt a conformational structure where the hydroxyl groups are directed away from the simvastatin, leaving the backbone structure free for hydrophobic interactions. Another interesting finding involves fluorene-based conjugated polyelectrolytes (CPEs) [10]. Conjugated polyelectrolytes tend to aggregate in water, which limits its electrical conductivity and photoluminescence for practical applications [11-13]. Surfactants and co-solvents can be efficiently used to promote the disaggregation of CPEs [10,14,15]. Knaapila et al. [16] have found that poly(vinyl alcohol), with a molecular weight around 30,000-40,000 $\mathrm{g} \mathrm{mol}^{-1}$ also leads to the breakup of CPE structure, highlighting the occurrence of hydrophobic interactions promoting the disaggregation process. Such interesting PVA behavior has motivated us to investigate its effect on the transport properties, by diffusion, of non-associated electrolytes. For that, we have used as reference the Hofmeister series [17,18] (Fig. 2). This series, proposed by Franz Hofmeister in 1888 [19] described the solubility of proteins in different electrolyte aqueous solutions. After that study, the series have been used to interpret the behavior and the effect of ions on the structure of water, and on the solubility of different macromolecules [20-22]. 


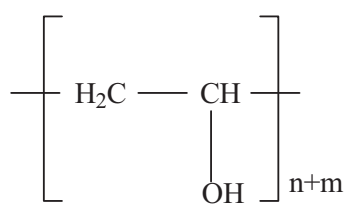

(a)

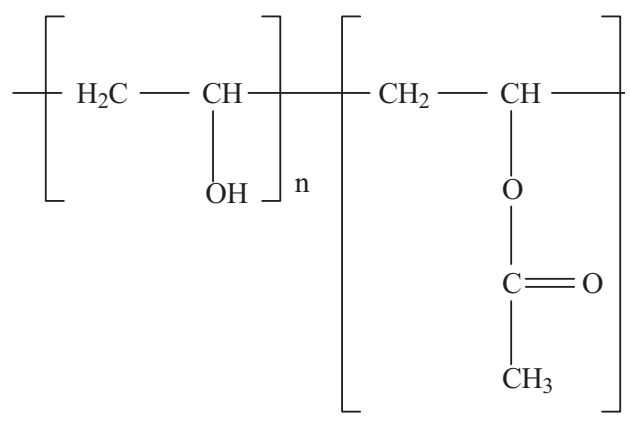

(b)

Fig. 1. Molecular structure of fully hydrolyzed (a) and partially hydrolyzed (b) PVA.

We proposed an experimental study of the binary diffusion for systems containing water and PVA over the concentration range from (0.001 to 0.227$) \mathrm{mol} \mathrm{dm}^{-3}$, by using Taylor's dispersion technique at $25{ }^{\circ} \mathrm{C}$. From these experimental diffusion results, the diffusion coefficient at infinitesimal concentration $D^{0}$, the thermodynamic factors, $F_{\mathrm{T}}$, and the activity coefficients were estimated by using the Nernst and Onsager-Fuoss equations [23-25], respectively, permitting us to have a better understanding of its thermodynamics in aqueous solutions. These studies were complemented by structural information obtained from NMR spectroscopy.

\section{Experimental}

\subsection{Materials}

Poly(vinyl alcohol), sodium chloride and sodium sulfate were supplied from Sigma-Aldrich and they were used as received (Table S1). For the NMR measurements, solutions were prepared with $\mathrm{D}_{2} \mathrm{O}$ (Aldrich $>0.99$ ). The $\mathrm{pH}^{*}$ values quoted is the direct $\mathrm{pH}$-meter readings (room temperature) after standardization with aqueous $\left(\mathrm{H}_{2} \mathrm{O}\right)$ buffers [26]. The solutions for the diffusion measurements were prepared using Millipore-Q water ( specific resistance $=1.82 \times 10^{5} \Omega \mathrm{m}$, at $25^{\circ} \mathrm{C}$ ). All solutions were freshly prepared at $25^{\circ} \mathrm{C}$ before each experiment.

\subsection{NMR experiments}

The ${ }^{1} \mathrm{H}$ and ${ }^{23} \mathrm{Na}$ NMR spectra were obtained using a Bruker Avance III HD $500 \mathrm{MHz}$ NMR spectrometer. The methyl signal of tert-butyl alcohol was used as the internal reference for ${ }^{1} \mathrm{H}(\delta 1.3)$ and the ${ }^{23} \mathrm{Na}$ signal of a $\mathrm{D}_{2} \mathrm{O}$ solution of $\mathrm{NaCl} 0.0089 \mathrm{~mol} \mathrm{~kg}^{-1}$ is used as the external reference for ${ }^{23} \mathrm{Na}$.

\subsection{Dynamic light scattering measurements (DLS)}

Hydrodynamic diameters of PVA solutions in water $\left(c_{1}=5 \mathrm{~g} \mathrm{dm}^{-3}\right)$ and salts $\left(c_{2}=0.02 \mathrm{~mol} \mathrm{dm}^{-3}\right)$ were determined by dynamic light scattering (DLS) on a Zetasizer Nano ZS90 instrument (Malvern Instruments, Malvern, UK) and expressed as intensity-weighted, z-average diameters $(\mathrm{nm})$. Analyses were carried out on samples diluted in solutions of respective salts $\left(\mathrm{NaCl}, \mathrm{Na}_{2} \mathrm{SO}_{4}\right)$ at a scattering angle of $173^{\circ}$. Prior to measurements, all samples were filtered through a $0.45 \mu \mathrm{m}$ syringe filter (Millipore, UK). The DLS measurements were performed at $25.0 \pm 0.1^{\circ} \mathrm{C}$. Each sample was measured for four times and subsequently the mean and standard deviation were calculated.

\subsection{Diffusion measurements}

In last years, Taylor dispersion has become increasingly popular for measuring mutual diffusion coefficients (chemical interdiffusion) in liquids and in mixtures, permitting to obtain data with an inaccuracy of $1-2 \%$. Having in mind this technique is well described in the literature [27-31], only a summary description of the procedure and equipment is here presented.

The usual procedure is to inject a small volume of solution containing solute at some concentration into a laminar carrier stream of different composition. As the injected sample flows through a long capillary tube with length and radius accurately measured, radial diffusion and convection along the tube axis shape the initial $\delta$ concentration pulse into a Gaussian profile. Binary mutual diffusion coefficients $(D)$ are calculated from the broadened distribution of the dispersed sample measured at the tube outlet (Eq. (1)). Extensions of this technique have been used to measure ternary and quaternary mutual diffusion
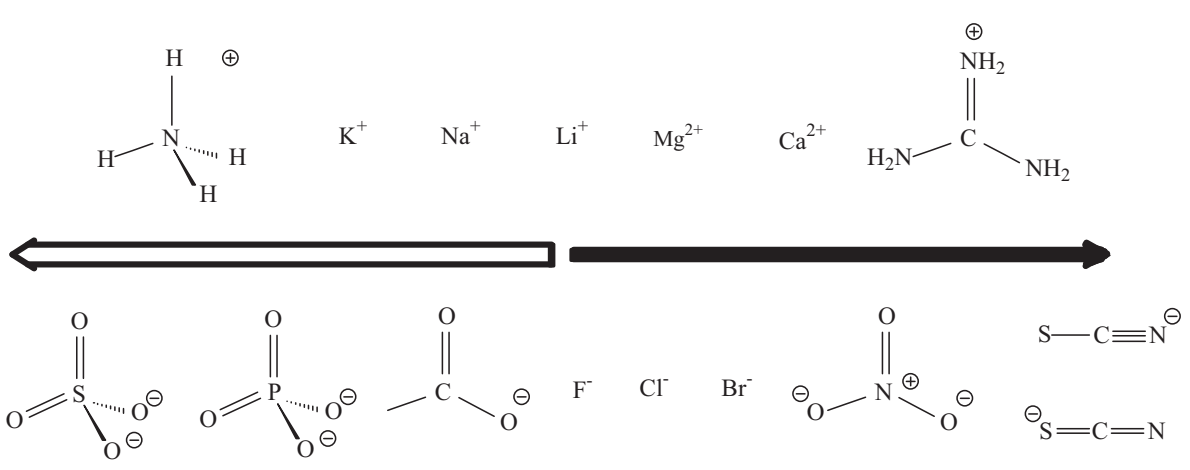
coefficients $\left(D_{\mathrm{ik}}\right)$ for multicomponent solutions [28]. These results include cross-coefficients $D_{\text {ik }}(i \neq k)$ describing the coupled fluxes of solutes driven by concentrations gradients in other solutes.

In our work, a capillary tube of the length and radius of 3.0480 ( \pm $0.0001) \times 10^{3} \mathrm{~cm}$ and $0.03220( \pm 0.00003) \mathrm{cm}$, respectively, was used. The method for obtaining these accuracy values are described in the literature [30]. At the start of each run, a 6-port Teflon injection valve (Rheodyne, model 5020) was used to introduce $0.063 \mathrm{~cm}^{3}$ of solution into the laminar carrier stream of slightly different composition. A flow rate of $0.23 \mathrm{~cm}^{3} \mathrm{~min}^{-1}$ (corresponding to 3.5 rotations per minute of the peristaltic pump head) has been used, and was controlled by a metering pump (Gilson model Miniplus 3) to give retention times of about $8 \times 10^{3} \mathrm{~s}$. The dispersion tube and the injection valve were kept at $25.00{ }^{\circ} \mathrm{C}\left( \pm 0.01{ }^{\circ} \mathrm{C}\right)$ in an air thermostat.

Dispersion of the injected samples was monitored using a differential refractometer (Waters model 2410) at the outlet of the dispersion tube. Detector voltages, $V(\mathrm{t})$, were measured at accurately $5 \mathrm{~s}$ intervals with a digital voltmeter (Agilent 34,401 A) with an IEEE interface. An example of the dispersion profile of $\mathrm{PVA} / \mathrm{Na}_{2} \mathrm{SO}_{4}$ standard experience is illustrated in Fig. S1 in Supplementary information.

Binary diffusion coefficients of PVA in water and in aqueous solutions were calculated by fitting the dispersion equation

$V(t)=V_{0}+V_{1} t+V_{\max }\left(t_{\mathrm{R}} / t\right)^{1 / 2} \exp \left[-12 D\left(t-t_{\mathrm{R}}\right)^{2} / r^{2} t\right]$

to the detector voltages. The additional fitting parameters were the mean sample retention time $t_{R}$, peak height $V_{\max }$, baseline voltage $V_{0}$, and baseline slope $V_{1}$.

In addition, values of tracer diffusion coefficients, $D_{\mathrm{T}}$, for PVA in aqueous solutions of sodium chloride and sodium sulfate were also measured. For these ternary systems, PVA(1)/ $\mathrm{NaCl}(2)$ and PVA/ (1)/ $\mathrm{Na}_{2} \mathrm{SO}_{4}(2)$, the following dispersion equation should be considered.

$V(t)=\bar{V}+V_{1} t+V_{\max }$
$\sqrt{\frac{t_{R}}{t}} \frac{\left(a+b \alpha_{1}\right) \sqrt{D_{1}} e^{-12 D_{1}\left(t-t_{R}\right)^{2 / r^{2} t}}+\left(1-a-b \alpha_{1}\right) \sqrt{D_{2}} e^{-12 D_{2}\left(t-t_{R}\right)^{2 / r^{2} t}}}{\left(a+b \alpha_{1}\right) \sqrt{D_{1}}+\left(1-a-b \alpha_{1}\right) \sqrt{D_{2}}}$

However, considering that the concentration of the salt under study (component 2) is significantly higher than the concentration of PVA (component 1), ensuring the occurrence of tracer diffusion, and that the concentrations of $\mathrm{NaCl}$ ( or $\mathrm{Na}_{2} \mathrm{SO}_{4}$ ) in the injection and carrier solutions are equal, the 2nd term inside square brackets in Eq. (2) is null and, consequently, Eq. (2) becomes equal to the Eq. (1), being $D=$ $D_{\text {Tracer }}[32-34]$.

\section{Results and discussion}

\subsection{NMR experiments}

As a first approach we aim to understand if the presence of ions, in particular sulfate and chloride, in solution would affect the structure of PVA. For that, we have obtained the ${ }^{1} \mathrm{H}$ and ${ }^{23} \mathrm{Na}$ NMR spectra of PVA in the presence of increasing concentrations of both $\mathrm{NaCl}$ and $\mathrm{Na}_{2} \mathrm{SO}_{4}$ salts. Figs. 3 and 4 and Figs. $\mathrm{S} 2$ and S3 (Supplementary information) show the dependence of the ${ }^{23} \mathrm{Na}$ and ${ }^{1} \mathrm{H}$ chemical shifts as function of the concentration of the $\mathrm{NaCl}$ and $\mathrm{Na}_{2} \mathrm{SO}_{4}$ added to a solution of PVA $0.0089 \mathrm{~mol} \mathrm{~kg}^{-1-}$, respectively.

Although the ${ }^{23} \mathrm{Na}$ NMR spectra show a noticeable shift to low frequencies in solutions of PVA/NaCl (Fig. 3) and PVA/ $\mathrm{Na}_{2} \mathrm{SO}_{4}$ (Fig. S2), the corresponding ${ }^{1} \mathrm{H}$ signals of PVA in the presence of increasing concentrations of both the salts are not affected, as is shown in Fig. 4 and Fig. S3. These observations can be regarded as an indication that the predominant interactions of both the salts, $\mathrm{NaCl}$ and $\mathrm{Na}_{2} \mathrm{SO}_{4}$, in solutions of PVA probably occur mostly with the solvent rather than with the polymeric chain, being the polymer conformations unaffected by the presence of the salts. Similar results we have previously obtained for the addition of $\mathrm{NaCl}$ to aqueous solutions of $\omega$-aminoacids, including $\gamma$ aminobutyric acid (GABA), $\delta$-aminopentanoic acid (DAPA) and $\varepsilon$ aminohexanoic acid (EAHA) $[35,36]$. Moreover, the width of ${ }^{1} \mathrm{H}$ and ${ }^{23} \mathrm{Na}$ signals does not change significantly, which suggest that the viscosity of the solution of PVA is not substantially changed with the addition of salts to the solution.

\subsection{Dynamic light scattering measurements (DLS)}

DLS measurements showed that hydrodynamic diameter of PVA in water differed in comparison with PVA dissolved in used salt solutions (Table 1).

The largest hydrodynamic diameter was found out for PVA dissolved in water $(48.0 \pm 6 \mathrm{~nm})$. On the contrary, $\mathrm{z}$-average diameters for PVA in $\mathrm{NaCl}$ were the smallest $\left(37.0 \pm 1 \mathrm{~nm}\right.$ ). PVA in the $\mathrm{Na}_{2} \mathrm{SO}_{4}$ solutions behaved differently, and its hydrodynamic diameters were larger ( $41.0 \pm$ $5 \mathrm{~nm}$ ) than that of $\mathrm{NaCl}(37.0 \pm 1 \mathrm{~nm})$. The reason of this behaviour could be seen in the different effect of the ion from the Hofmeister series on the PVA. $\mathrm{Na}_{2} \mathrm{SO}_{4}$ salt containing a kosmotropic cation and kosmotropic anion, whereas $\mathrm{NaCl}$ salt is a combination of a kosmotropic anion and chaotropic cation [37]. Additionally, differences in particle size were also observed in distribution curve. PVA in water showed the presence of trimodal distributions indicating the presence of a three particle population. Narrow bimodal distribution curve confirmed

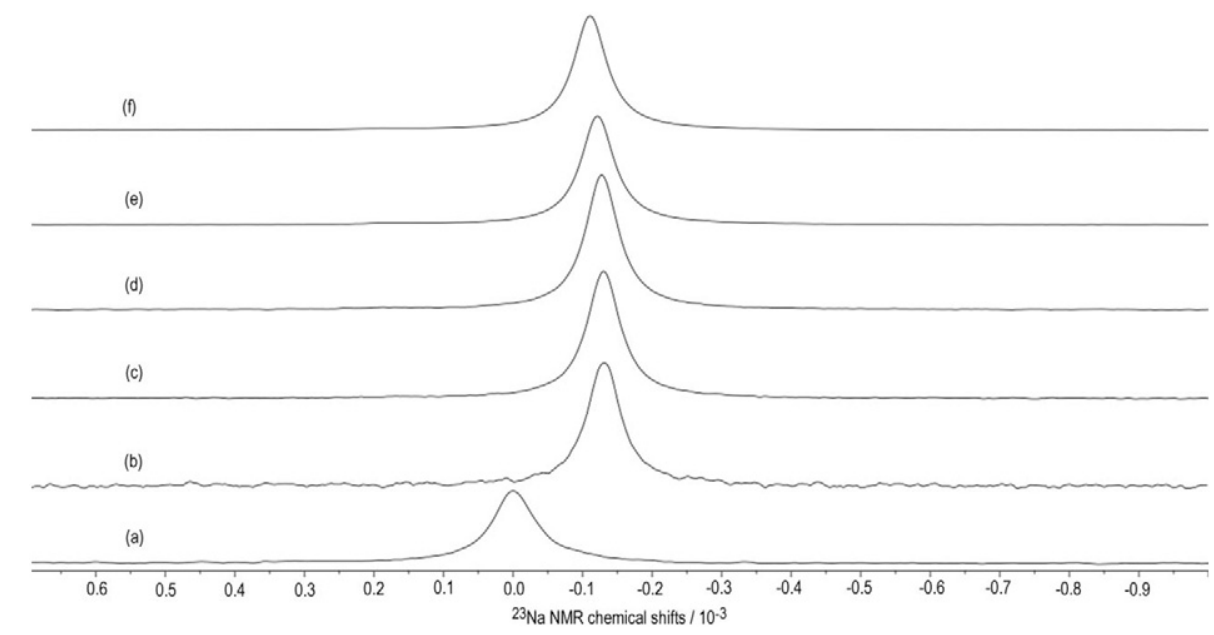

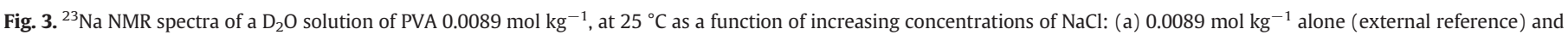
(b) $0.0045 \mathrm{~mol} \mathrm{~kg}^{-1}$; (c) $0.0089 \mathrm{~mol} \mathrm{~kg}-1$; (d) $0.0178 \mathrm{~mol} \mathrm{~kg}^{-1}$; (e) $0.0445 \mathrm{~mol} \mathrm{~kg}^{-1}$ and (f) $0.0890 \mathrm{~mol} \mathrm{~kg}^{-1}$. 


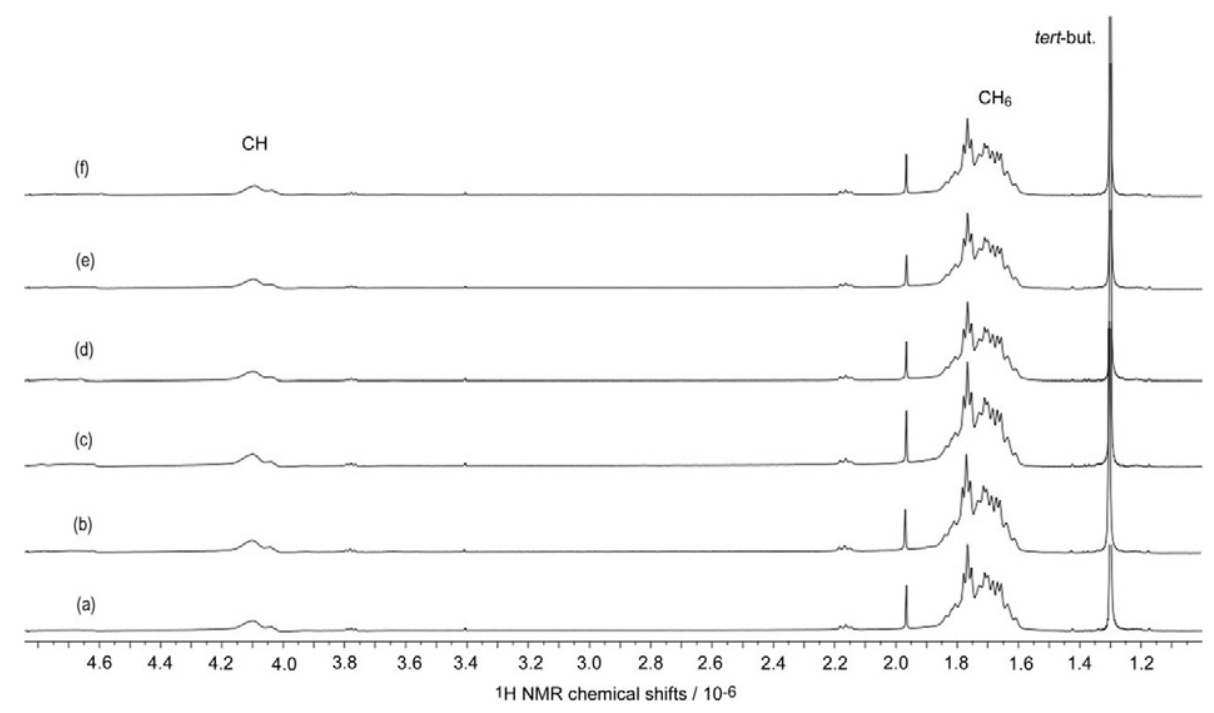

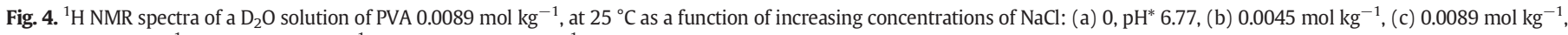
(d) $0.0178 \mathrm{~mol} \mathrm{~kg}^{-1}$, (e) $0.0445 \mathrm{~mol} \mathrm{~kg}^{-1}$ and (f) $0.0890 \mathrm{~mol} \mathrm{~kg}^{-1}$.

the presence of a two particle population in PVA dissolved in $\mathrm{NaCl}$ solution. Finally, PVA in the $\mathrm{Na}_{2} \mathrm{SO}_{4}$ solutions confirmed narrow trimodal distributions indicating the presence of a three particle population.

\subsection{Analysis of diffusion coefficients data by using Hartley model}

The experimental diffusion coefficients, $D$, of PVA in aqueous solutions in the absence and presence of the electrolytes are shown in Tables 2 and 3, respectively. For each system, the limiting diffusion coefficients at infinitesimal concentration, $D^{0}$, were computed by fitting a linear equation to the experimental data by using a least-squares method (Eqs. (3) and (4)). The goodness of the fit (obtained with a confidence interval of $98 \%$ ) can be assessed by a high determination coefficient, $R^{2}$, that is, equal 0.996 and 0.997 , and the low percentage of standard deviation $(<1 \%)$. Both values for $D^{0}$ are acceptable, having in mind that the differences between them $(2 \%)$ are within the method's uncertainty $(<3 \%)$.

$D /\left(10^{-9} \mathrm{~m}^{2} \mathrm{~s}^{-1}\right)=0.242( \pm 0.001)-0.166( \pm 0.008) c\left(R^{2}=0.992\right)$

$D /\left(10^{-9} \mathrm{~m}^{2} \mathrm{~s}^{-1}\right)=0.248( \pm 0.002)-0.16( \pm 0.01) c\left(R^{2}=0.993\right)(4$

The interpretation of the dependence of concentration on the diffusion coefficients of PVA in aqueous solutions may be done by using the Onsager-Fuoss theory [23-25] (Eq. (5)). This theory is based on the assumption that $D$ is a product of two factors: a kinetic one, $F_{\mathrm{M}}$ (or molar mobility coefficient of a diffusing substance) and a thermodynamic one, $F_{\mathrm{T}}$ That is,

$D=F_{\mathrm{M}} F_{\mathrm{T}}$

Table 1

Hydrodynamic diameters (z-average diameter) of PVA coil in deionized water and in aqueous solutions of salts $\left(\mathrm{NaCl}, \mathrm{Na}_{2} \mathrm{SO}_{4}\right)$.

\begin{tabular}{ll}
\hline Sample & z-Average diameter/(nm) \\
\hline PVA water & $48 \pm 6$ \\
PVA NaCl & $37 \pm 1$ \\
PVA Na & $\mathrm{SO}_{4}$ \\
\hline
\end{tabular}

being

$F_{\mathrm{M}}=\left(D^{0}+\Delta_{1}+\Delta_{2}\right)$

and

$F_{\mathrm{T}}=\left(1+c \frac{\partial 1 n \gamma}{\partial c}\right)$

where $D^{0}$ and $D$ represent the diffusion coefficients of PVA at infinitesimal and finite concentrations, respectively; $\Delta_{1}$ and $\Delta_{2}$, the first and second-order electrophoretic terms [23-25], respectively; and $\gamma$, the mean molar activity coefficient of PVA entities. However, taking into account that the values found for the binary diffusion coefficients (Table 3 ) into the concentration range studied are fairly constant, the Eq. (5) can be simplified to Eq. (8), if assuming that the effect of the electrophoretic terms on the diffusion coefficient is considered negligible (or, in other words, $F_{\mathrm{M}}=D^{0}$ ). That is,

$D=D^{0}\left(1+c \frac{\partial 1 n \gamma}{\partial c}\right)$

where $\gamma$ is the thermodynamic activity coefficient of the solute. On the other words, considering that the variation of diffusion coefficients for the concentration range studied is small, we assume that PVA, when diffusing in aqueous solutions, behaves as a nonelectrolyte. In those circumstances, and using our results (Table 3), the thermodynamic factor, $F_{\mathrm{T}}$, values have been estimated at the concentrations studied (Table 4).

Eq. (7), known by Hartley's equation [25], despite to be limited to the analysis of diffusion in dilute solutions of non-ionic and nonassociating solutes because variations in the viscosity with concentration and the counter flow of solvent relative to the solute are neglected, is very useful to estimate thermodynamic parameters (i.e., thermodynamic factor, $F_{\mathrm{T}}$ and activity coefficients) (Table 4 ).

Combining Hartley's equation (8) and the Eq. (9) [38],

$\ln \gamma=B c$

we obtain the Eq. (10)

$D /\left(10^{-9} \mathrm{~m}^{2} \mathrm{~s}^{-1}\right)=D 0\left[1+B c /\left(\mathrm{mol} \mathrm{dm}^{-3}\right)\right]$ 
Table 2

Binary diffusion coefficients of aqueous PVA solutions, at different concentrations $c$, using water as a carrier flow, at $25^{\circ} \mathrm{C}$.

\begin{tabular}{|c|c|c|}
\hline$c /\left(\mathrm{g} \cdot \mathrm{dm}^{-3}\right)$ & $c_{\mathrm{m}} /\left(\mathrm{mol} \mathrm{dm}^{-3}\right)^{\mathrm{a}}$ & $D /\left(10^{-9} \mathrm{~m}^{2} \mathrm{~s}^{-1}\right)$ \\
\hline 1.0 & 0.0227 & 0.240 \\
\hline 1.5 & 0.0341 & 0.236 \\
\hline 2.0 & 0.0455 & 0.235 \\
\hline 3.0 & 0.0682 & 0.229 \\
\hline 5.00 & 0.1136 & 0.223 \\
\hline 10.0 & 0.2273 & 0.205 \\
\hline
\end{tabular}

${ }^{\text {a }} c_{\mathrm{m}}=\frac{C}{M}$, where $c_{\mathrm{m}}$ and $M$ represent the monomer concentration PVA and its monomer molar mass $\left(M=44 \mathrm{~g} \mathrm{~mol}^{-1}\right)$, respectively.

Table 3

Binary diffusion coefficients of PVA measured from PVA solutions at different concentrations, $c$, ${ }^{\text {a }}$ at $25^{\circ} \mathrm{C}$.

\begin{tabular}{|c|c|c|}
\hline$c /\left(\mathrm{g} \mathrm{dm}^{-3}\right)$ & $c_{m} /\left(\mathrm{mol} \mathrm{dm}^{-3}\right)^{\mathrm{b}}$ & $D /\left(10^{-9} \mathrm{~m}^{2} \mathrm{~s}^{-1}\right)$ \\
\hline 2.5 & 0.0568 & 0.239 \\
\hline 5.0 & 0.1136 & 0.228 \\
\hline 7.5 & 0.1704 & 0.221 \\
\hline 10.0 & 0.2273 & 0.210 \\
\hline
\end{tabular}

a These experiments were carried out by using PVA carrier solutions of concentration $c /\left(\mathrm{g} \mathrm{dm}^{-3}\right)$, and the injected solutions $(c+\Delta c)$ differed in general, by $7.5 \mathrm{~g} / \mathrm{L}$ or less.

${ }^{\mathrm{b}} c_{\mathrm{m}}=\frac{c}{M}$, where $c_{\mathrm{m}}$ and $M$ represent the monomer concentration and the monomer molar mass $\left(M=44 \mathrm{~g} \mathrm{~mol}^{-1}\right)$ of PVA, respectively.

Having estimated $B$ value from the linear relationship fitted to our diffusion coefficients $\left(B=-0.665 \mathrm{dm}^{3} \mathrm{~mol}^{-1}\right.$ ) and the Eq. (10), the values for the activity coefficient, in the concentration range studied, were computed and collected in Table 4. From the analysis of this table, it can be seen that the gradient of the free energy or thermodynamic factor $\left(F_{\mathrm{T}}\right)$, as well as the activity coefficient $(\gamma)$ of PVA, decreases when its concentration increases, leading us to conclude that the interactions PVA and water molecules are responsible by a transport of an appreciable fraction of larger aggregates, having a lower mobility than the non hydrated PVA. The gain hydration water from PVA macromolecules will lead to large resistance to motion through the liquid and, consequently, a lower diffusion coefficient.

\subsection{Effect of electrolytes on tracer diffusion of poly(vinyl alcohol) in aque- ous solutions}

Tables 5 and 6 show our experimental values of $D$ for PVA measured at tracer concentrations in aqueous solutions of sodium chloride and sodium sulfate, respectively, at different concentrations (that is, $c=0.02$, 0.05 and $0.10 \mathrm{~mol} \mathrm{dm}^{-3}$ ).

From Tables 5 and 6, it can be observed that the tracer diffusion coefficients of PVA decrease as its concentration increases, independently of the concentration of electrolyte.

However, in aqueous solutions containing $\mathrm{NaCl}\left(\right.$ or $\mathrm{Na}_{2} \mathrm{SO}_{4}$ ), the deviations between the tracer diffusion coefficient values $\left(D_{\text {Tracer }}\right)$ in these supporting electrolytes and the limiting diffusion coefficients of the PVA in water $\left(D^{0}\right)$, at the same temperature and at infinitesimal concentration of PVA $(c \rightarrow 0)$, are positive (i.e., $\Delta D^{0} / D^{0}=8 \%$ and $69 \%$, for $\mathrm{NaCl}$ and $\mathrm{Na}_{2} \mathrm{SO}_{4}$, respectively).

The increase in the $D^{0}$ values for both aqueous systems containing these salts when compared with $D^{0}$ value in water, as well as the gradient of chemical potential, indicates the presence of salting-out effects (Tables 2,3). In fact, previous diffusion studies involving interactions between ions and macromolecules, such as proteins [24], show that sulfate ion is a strongly hydrated ion, known as water structure maker; consequently, its presence will not favor interactions between PVA and water molecules. PVA-PVA interactions thus become stronger than the water-PVA interactions and the PVA molecules may associate by hydrogen bonds interactions. It is also worth noticing that the positive deviation for $\Delta D^{0} / D^{0}$ can be explained by the non-neglecting role of sodium ions as a water structure-making. Thus, as a consequence of predominant electrolyte-water interactions, the PVA conformations remain unaffected, as it was discussed in the previous section.

The entities of PVA offer less frictional resistance to motion through the liquid and, consequently, the diffusion coefficient of this aqueous system becomes higher.

These facts are also supported by the analysis of hydrodynamic radii of PVA, as seen by DLS, in the presence of $\mathrm{NaCl}$ and $\mathrm{Na}_{2} \mathrm{SO}_{4}$ solutions when compared with those obtained in the absence of salt (Table 1). Such values clearly suggest that the presence of $\mathrm{NaCl}$ and $\mathrm{Na}_{2} \mathrm{SO}_{4}$ does not favor the interactions between PVA and water molecules leading to lower radii and consequently higher diffusion coefficients.

\section{Conclusions}

The mutual diffusion coefficients for PVA in water, and in aqueous solutions without and with sodium chloride and sodium sulfate at $25{ }^{\circ} \mathrm{C}$ were measured.

In view of obtaining higher diffusion coefficients values in solutions containing these salts and in trace concentrations of PVA, when compared with those obtained in the absence of these same salts, we can conclude that the diffusion of this polymer in aqueous solutions is strongly affected by the presence of these electrolytes as a result of the salting-out effect, being more favorable at high salt concentrations and at infinitesimal concentration of PVA. The presence of both salts does not favor the interactions PVA and water molecules, and

Table 4

Comparison of thermodynamic parameters, $\left(F_{\mathrm{T}}\right.$ and $\left.\gamma\right)$, of PVA in aqueous solutions at $25^{\circ} \mathrm{C}$.

\begin{tabular}{|c|c|c|}
\hline$c /\left(\mathrm{mol} \mathrm{dm}^{-33}\right)^{\mathrm{a}}$ & $F_{\mathrm{T}} /\left(10^{-99} \mathrm{~m}^{2} \mathrm{~s}^{-11}\right)^{\mathrm{b}}$ & $\gamma^{c}$ \\
\hline 0.0568 & 0.964 & 0.9628 \\
\hline 0.1136 & 0.919 & 0.9270 \\
\hline 0.1704 & 0.891 & 0.8925 \\
\hline 0.2273 & 0.847 & 0.8593 \\
\hline
\end{tabular}

${ }^{\text {a }} c_{\mathrm{M}}=\frac{c}{M}$, where $c_{\mathrm{m}}$ and $M$ represent the monomer concentration PVA and its monomer molar mass $\left(M=44 \mathrm{~g} \mathrm{~mol}^{-1}\right)$, respectively.

b $F_{\mathrm{T}}=D_{\exp }^{\prime} / D^{0}$, where $D_{\exp }, F_{\mathrm{T}}$ and $D^{0}$ represent our data (Table 3 ), thermodynamic factor and diffusion coefficient at infinitesimal concentration, respectively.

c Activity coefficients, $\gamma$, estimated from Eq. (10), where $B=-0.665 \mathrm{dm}^{3} \mathrm{~mol}^{-1}$, representing $B$ the thermodynamic coefficient. 
Table 5

Tracer diffusion coefficients, $D_{\text {Tracer, }}$, for PVA (component 1 ) in aqueous solutions containing $\mathrm{NaCl}$ (component 2) at different concentrations, $c_{2}$, and at $25^{\circ} \mathrm{C}^{\mathrm{a}}$

\begin{tabular}{|c|c|c|c|}
\hline$c_{1} /\left(\mathrm{mol} \mathrm{dm}^{-3}\right)$ & $\begin{array}{l}D_{\text {Tracer }} /\left(10^{-9} \mathrm{~m}^{2} \mathrm{~s}^{-1}\right) \\
\left(C_{2}=0.02 \mathrm{~mol} \mathrm{dm}^{-3}\right)\end{array}$ & $\begin{array}{l}D_{\text {Tracer }} /\left(10^{-9} \mathrm{~m}^{2} \mathrm{~s}^{-1}\right) \\
\left(C_{2}=0.05 \mathrm{~mol} \mathrm{dm}^{-3}\right)\end{array}$ & $\begin{array}{l}D_{\text {Tracer }} /\left(10^{-9} \mathrm{~m}^{2} \mathrm{~s}^{-1}\right) \\
\left(C_{2}=0.10 \mathrm{~mol} \mathrm{dm}^{-3}\right)\end{array}$ \\
\hline 0.0455 & 0.266 & 0.265 & 0.255 \\
\hline 0.1136 & 0.224 & 0.251 & 0.246 \\
\hline 0.2273 & $\begin{array}{l}\left.D_{\text {Tracer }}^{0} C_{(\mathrm{PVA}) \rightarrow 0}\right)=0.276 \times 10^{-9} \mathrm{~m}^{2} \mathrm{~s}^{-1} \\
\left(\Delta D_{\text {Tracer }} / D^{0}=14 \%\right)^{\mathrm{b}}\end{array}$ & $\begin{array}{l}\left.D_{\text {Tracer }}^{0} C_{(\mathrm{PVA}) \rightarrow 0}\right)=0.272 \times 10^{-9} \mathrm{~m}^{2} \mathrm{~s}^{-1} \\
\left(\Delta D_{\text {Tracer }} / D^{0}=12 \%\right)^{\mathrm{b}}\end{array}$ & $\begin{array}{l}\left.D_{\text {Tracer }}^{o} \mathcal{C}_{(\mathrm{PVA}) \rightarrow 0}\right)=0.263 \times 10^{-9} \mathrm{~m}^{2} \mathrm{~s}^{-1} \\
\left(\Delta D_{\text {Tracer }} / D^{0}=8 \%\right)^{\mathrm{b}}\end{array}$ \\
\hline
\end{tabular}

${ }^{a}$ This table shows the values of tracer diffusion coefficients of PVA in sodium chloride aqueous solutions. To get those values, 70 $\mu$ Lof PVA $+\mathrm{NaCl}$ at concentrations, $c_{1}$ and $c_{2}$, respectively, was injected into the flow sodium chloride solution, at concentration $c_{2}$.

${ }^{\mathrm{b}} \Delta D_{\text {Tracer }} / D^{0}$ represent the deviations between tracer and the diffusion coefficients of PVA at infinitesimal concentration (i.e., $D^{0}=0.242 \times 10^{-9} \mathrm{~m}^{2} \mathrm{~s}^{-1}$ ).

Table 6

Tracer diffusion coefficients, $D_{\text {Tracer, }}$, for PVA (component 1 ) in aqueous solutions containing $\mathrm{Na}_{2} \mathrm{SO}_{4}$ (component 2 ) at different concentrations, $c_{2}$, and at $25^{\circ} \mathrm{C}^{\mathrm{a}}$

\begin{tabular}{llll}
\hline$c_{1} /\left(\mathrm{mol} \mathrm{dm}^{-3}\right)$ & $\begin{array}{l}D_{\text {Tracer }} /\left(10^{-9} \mathrm{~m}^{2} \mathrm{~s}^{-1}\right) \\
\left(C_{2}=0.02 \mathrm{~mol} \mathrm{dm}^{-3}\right)\end{array}$ & $\begin{array}{l}D_{\text {Tracer }} /\left(10^{-9} \mathrm{~m}^{2} \mathrm{~s}^{-1}\right) \\
\left(C_{2}=0.05 \mathrm{~mol} \mathrm{dm}^{-3}\right)\end{array}$ & $\begin{array}{l}D_{\text {Tracer }} /\left(10^{-9} \mathrm{~m}^{2} \mathrm{~s}^{-1}\right) \\
\left(C_{2}=0.10 \mathrm{~mol} \mathrm{dm}\right.\end{array}$ \\
\hline 0.0455 & 0.300 & 0.285 & 0.380 \\
0.1136 & 0.280 & 0.239 & 0.340 \\
0.2273 & 0.233 & 0.200 & 0.270 \\
& $D_{\text {Tracer } \rightarrow 0}=0.319 \times 10^{-9} \mathrm{~m}^{2} \mathrm{~s}^{-1}$ & $D_{\text {Tracer } \rightarrow 0}=0.330 \times 10^{-9} \mathrm{~m}^{2} \mathrm{~s}^{-1}$ & $D_{\text {Tracer } \rightarrow 0}=0.410 \times 10^{-9} \mathrm{~m}^{2} \mathrm{~s}^{-1}$ \\
$\left(\Delta D_{\text {Tracer }} / D^{0}=69 \%\right)^{\mathrm{b}}$ & $\left(\Delta D_{\text {Tracer }} / D^{0}=36 \%\right)^{\mathrm{b}}$ & \\
\hline
\end{tabular}

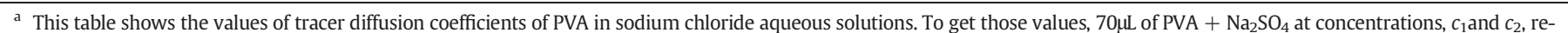
spectively, was injected into the flow sodium sulfate solution, at concentration $c_{2}$.

${ }^{\mathrm{b}} \Delta D_{\mathrm{Trace}} / D^{0}$ represent the deviations between tracer and the diffusion coefficients of PVA in water at infinitesimal concentration (i.e., $D^{0}=0.242 \times 10^{-9} \mathrm{~m}^{2} \mathrm{~s}^{-1}$ ).

consequently, the polymer conformations unaffected by their presence. These facts are also supported by NMR spectroscopy and DLS measurements.

Diffusion coefficients measured for aqueous solutions of systems containing PVA and salts provide transport data necessary to model the diffusion in pharmaceutical and engineering applications.

\section{Acknowledgments}

The authors in Coimbra are grateful for funding from "The Coimbra Chemistry Centre" which is supported by the Fundação para a Ciência e a Tecnologia (FCT), Portuguese Agency for Scientific Research, through the programmes UID/QUI/UI0313/2020 and COMPETE. NMR data were obtained at the UC-NMR facility which is supported in part by FEDER European Regional Development Fund through the COMPETE Programme and by National Funds by FCT, through grants REEQ/481/QUI/ 2006, RECI/QEQ-QFI/0168/2012, CENTRO-07-CT62-FEDER-002012, and the Rede Nacional de Ressonância Magnética Nuclear (RNRMN) B. Filova is thankful for funding from Erasmus+ programme of the European Union 2018/19. The authors in Zlín are grateful for research funding by the Ministry of Education, Youth, and Sports of the Czech Republic, Program NPU I (LO1504).

\section{Declaration of competing interest}

The authors declare that they have no known competing financial interests or personal relationships that could have appeared to influence the work reported in this paper.

\section{Appendix A. Supplementary data}

Supplementary data to this article can be found online at https://doi. org/10.1016/j.molliq.2020.112728.

\section{References}

[1] H.N. Fard, G.B. Pour, M.N. Sarvi, PVA-based supercapacitors, Ionics, P. Esmaili, Ionics 25 (2019) 2951-2963, https://doi.org/10.1007/s11581-019-03048-8.

[2] J.H. Jang, J.I. Han, Cylindrical relative humidity sensor based on poly-vinyl alcohol (PVA) for wearable computing devices with enhanced sensitivity, Sensors Actuators A Phys. 261 (2017) 268, https://doi.org/10.1016/j.sna.2017.05.011.
[3] J. Zhang, G. Jiang, T. Cumberland, P. Xu, Y. Wu, S. Delaat, A. Yu, Z. Chen, A highly sensitive breathable fuel cell gas sensor with nanocomposite solid electrolyte, Info. Mat (ISSN: 2567-3165) 1 (2019) 234, https://doi.org/10.1002/inf2.12017.

[4] C.M. Hassan, N.A. Peppas, Structure and applications of poly(vinyl alcohol) hydrogels produced by conventional crosslinking or by freezing/thawing methods, Adv. Polym. Sci. 153 (2000) 37-65, https://doi.org/10.1007/3-540-46414-X_2.

[5] S. Patachia, Poly (Vinyl Alcohol) [PVA]-Based Polymer Membranes, Nova Science Publishers, 2009.

[6] A. Papancea, A.J.M. Valente, S. Patachia, M.G. Miguel, B. Lindman, PVA-DNA cryogel membranes: characterization, swelling, and transport studies, Langmuir 24 (2008) 273-279, https://doi.org/10.1021/la702639d.

[7] T.S. Anirudhan, J. Parvathy, A.S. Nair, A novel composite matrix based on polymeric micelle and hydrogel as a drug carrier for the controlled release of dual drugs, Carbohydr. Polym. 136 (2016) 1118-1127, https://doi.org/10.1016/j.carbpol.2015. 10.019 .

[8] A. Aytimur, İ. Uslu, Polym.-Plast. Technol. Eng. 53 (2014) 655-660, https://doi.org/ 10.1080/03602559.2013.874031.

[9] J.G.C. Baptista, S.P.J. Rodrigues, A.F.Y. Matsushita, C. Vitorino, T.M.R. Maria, H.D. Burrows, A.A.C.C. Pais, A.J.M. Valente, Does poly(vinyl alcohol) act as an amphiphilic polymer? An interaction study with simvastatin, J. Mol. Liquids 222 (2016) 287-294, https://doi.org/10.1016/j.molliq.2016.07.025.

[10] H.D. Burrows, A.J.M. Valente, T. Costa, B. Stewart, M.J. Tapia, U. Scherf, What conjugated polyelectrolytes tell us about aggregation in polyelectrolyte/surfactant systems, J. Mol. Liquids 210 (2015) 82-99, https://doi.org/10.1016/j.molliq.2015.04. 012.

[11] H.N. Kim, Z. Guo, W. Zhu, J. Yoon, H. Tian. Recent progress on polymer-based fluorescent and colorimetric chemosensors. Chem. Soc. Rev., 40(1), 79-93. doi:https:// doi.org/10.1039/c0cs00058b.

[12] A. Duarte, K.-Y. Pu, B. Liu, G.C. Bazan, Recent advances in conjugated polyelectrolytes for emerging optoelectronic applications, Chem. Mater. 23 (2011) 501-515, https:// doi.org/10.1021/cm102196t

[13] H.D. Burrows, T. Costa, M.L. Ramos, A.J.M. Valente, B. Stewart, L.L.G. Justino, A.I.A. Almeida, N.L. Catarina, R. Mallavia, M. Knaapila, Self-assembled systems of water soluble metal 8-hydroxyquinolates with surfactants and conjugated polyelectrolytes, Phys. Chem. Chem. Phys. 18 (2016) 16629-16640, https://doi.org/10.1039/ C5CP07085F.

[14] H.D. Burrows, V.M.M. Lobo, J. Pina, M.L. Ramos, J. Seixas de Melo, A.J.M. Valente, M.J. Tapia, S. Pradhan, U. Scherf, Fluorescence enhancement of the water- soluble poly \{1,4-phenylene-[9,9-bis-(4-phenoxybutylsulfonate)]fluorene-2,7-diyl\} copolymer in n-dodecylpentaoxyethylene glycol ether micelles, Macromolecules 37 (2004) 7425-7427, https://doi.org/10.1021/ma048780.

[15] L.M. Martelo, S.M. Fonseca, A.T. Marques, H.D. Burrows, A.J.M. Valente, L.L.G. Justino, U. Scherf, S. Pradhan, Q. Song, Effects of charge density on photophysics and aggregation behavior of anionic fluorene-arylene conjugated polyelectrolytes, Polymers 10 (2018) 258-300, https://doi.org/10.3390/polym10030258.

[16] M. Knaapila, B. Stewart, T. Costa, S.E. Rogers, J. Pragana, S.M. Fonseca, A.J.M. Valente, M.L. Ramos, D. Murtinho, J.C. Pereira, R. Mallavia, H.D. Burrows, Incorporation of a cationic conjugated polyelectrolyte CPE within an aqueous poly(vinyl alcohol), Macromolecules 49 (2016) 9119-9131, https://doi.org/10.1021/acs.macromol.6b01895.

[17] N. Schwierz, D. Horinek, R.R. Netz, Anionic and cationic Hofmeister effects on hydrophobic and hydrophilic surfaces, Langmuir 29 (2013) 2602-2614, https://doi.org/ 10.1021/la303924e. 
[18] Y. Zhang, P.S. Cremer, Chemistry of Hofmeister anions and osmolytes, Annu. Rev. Phys. Chem. 61 (2010) 63--83, doi:https://doi.org/10.1146/annurev.physchem. 59.032607.093635.

[19] W. Kunz, J. Henle, B.W. Ninham, Zur Lehre von der Wirkung der Salze (about the science of the effect of salts): Franz Hofmeister's historical papers. Curr. Opin. Colloid Interface Sci. 9 (2004) 19--37, doi:https://doi.org/10.1016/j.cocis.2004.05.005.

[20] Y. Marcus, Effect of ions on the structure of water: structure making and breaking, Chem. Rev. 109 (2009) 1346-1370, https://doi.org/10.1021/cr8003828.

[21] Y. Marcus, Effect of ions on the structure of water, Pure Appl. Chem. (2010) 1889-1899, https://doi.org/10.1351/pac-con-09-07-02.

[22] Y. Zhang, S. Furyk, D.E. Bergbreiter, P.S. Cremer, Specific ion effects on the water solubility of macromolecules, PNIPAM and the Hofmeister series, J. Am. Chem. Soc. 127 (2005) 14505-14510, https://doi.org/10.1021/ja0546424.

[23] T. Erdey-Grúz, Transport Phenomena in Aqueous Solutions, Hilger (Adam), 1974.

[24] R.A. Robinson, R.H. Stokes, Electrolyte Solutions: Second Revised Edition, Dover Publications, Incorporated, 2012.

[25] H.J.V. Tyrrell, K.R. Harris, Diffusion in Liquids: A Theoretical and Experimental Study, Butterworths, 1984

[26] R.M.C. Dawson, Data for Biochemical Research, Oxford University Press, Oxford [Oxfordshire, 1982.

[27] J. Barthel, H.J. Gores, C.M. Lohr, J.J. Seidl, Taylor dispersion measurements at low electrolyte concentrations. I. Tetraalkylammonium perchlorate aqueous solutions, J. Solut. Chem. 25 (1996) 921-935, https://doi.org/10.1007/BF00972589.

[28] R. Callendar, D.G. Leaist, Diffusion coefficients for binary, ternary, and polydisperse solutions from peak-width analysis of Taylor dispersion profiles, J. Solut. Chem. 35 (2006) 353-379, https://doi.org/10.1007/s10953-005-9000-2.

[29] I.M.S. Lampreia, Â.F.S. Santos, M.J.A. Barbas, F.J.V. Santos, M.L.S. Matos Lopes, Changes in aggregation patterns detected by diffusion, viscosity, and surface tension in water +2-(diethylamino)ethanol mixtures at different temperatures, J. Chem. Eng. 52 (2007) 2388-2394, https://doi.org/10.1021/je700350b.

[30] A.C.F. Ribeiro, V.M.M. Lobo, D.G. Leaist, J.J.S. Natividade, L.P. Veríssimo, M.C.F. Barros, A.M.T.D.P.V. Cabral, Binary diffusion coefficients for aqueous solutions of lactic acid J. Solut. Chem. 34 (2005) 1009-1016, https://doi.org/10.1007/s10953-005-6987-3.
[31] W. Low, Taylor dispersion technique for investigation of diffusion in liquids and its applications, Química Nova 20 (1997) 541-545, https://doi.org/10.1590/S010040421997000500015.

[32] T. Grossmann, J. Winkelmann, Ternary diffusion coefficients of cyclohexane toluuene + methanol by Taylor dispersion measurements at $298.15 \mathrm{~K}$. Part 1. Toluenerich area, J. Chem. Eng. Data 54 (2009) 405-410, https://doi.org/10.1021/ je800444e.

[33] D.M. Rodriguez L.M.P. Verissimo, M.C.F Barros, D.F. S. Rodrigues, M.M. Rodrigo, M.A. Esteso, C.M. Romero, A.C.F. Ribeiro, Limiting values of diffusion coefficients of glycine, alanine, $\alpha$-amino butyric acid, norvaline and norleucine in a relevant physiological aqueous médium, Eur. Phys. J. E. 40 (2017) 21, https://doi.org/10.1140/ epje/i2017-11511-y.

[34] L.M.P. Verissimo, G. Utzeri, M.L. Ramos, A.C.F. Ribeiro, A.J.M. Valente, Limiting diffusion coefficients of glufosinate ammonium, cymoxanil and imidacloprid in aqueous solutions, J. Mol. Liquids 293 (2019), 111459. https://doi.org/10.1016/j.molliq.2019. 111459.

[35] M.M. Rodrigo, M.A. Esteso, L.M.P. Veríssimo, C.M. Romero, M.L. Ramos, A.J.M. Valente, A.C.F. Ribeiro, A comparative study between the behavior diffusion of $\alpha$ aminobutyric acid and $\gamma$-aminobutyric acid in sodium chloride aqueous solutions, J. Mol. Liquids 291 (2019), 111289. https://doi.org/10.1016/j.molliq.2019.111289.

[36] C.M. Romero, G.P. Trujillo, L.M.P. Verissimo, M.A. Esteso, M.L. Ramos, A.C.F. Ribeiro, Limiting diffusion coefficients of $\alpha, \omega$-amino acids in water and in sodium chloride aqueous solutions at 298.15K, Eur. Phys. J. E 42 (2019) 94, https://doi.org/10.1140/ epje/i2019-11856-1.

[37] L. Musilová, V. Kašpárková, A. Mráček, A. Minařík, M. Minařík, The behaviour of hyaluronan solutions in the presence of Hofmeister ions: a light scattering, viscometry and surface tension study, Carbohydr. Polym. 212 (2019) 395-402, https://doi. org/10.1016/j.carbpol.2019.02.032.

[38] M. Koichiro, S. Masahiro, N. Masayuki, Viscosity B-coefficients, apparent molar volumes, and activity coefficients for $\alpha$ - and $\gamma$-cyclodextrins in aqueous solutions, Bull. Chem. Soc. Jpn. 56 (1983) 3556-3560, https://doi.org/10.1246/bcsj.56.3556. 